\title{
Analysis of atresia in equine follicles using histology, fresh granulosa cell morphology and detection of DNA fragmentation
}

\author{
H. G. Pedersen ${ }^{1}$, E. D. Watson ${ }^{1}$ and E. E. Telfer ${ }^{2}$ \\ ${ }^{1}$ Department of Veterinary Clinical Studies, University of Edinburgh, Easter Bush Veterinary Centre, \\ Roslin, Midlothian EH25 9RG, UK; and ${ }^{2}$ Institute of Cell and Molecular Biology, University of Edinburgh, \\ Darwin Building, Mayfield Road, Edinburgh EH9 3JR, UK
}

\begin{abstract}
Follicular atresia has been examined previously by various biochemical and histological methods. The aim of this study was to compare, for the first time, detection of granulosa cell apoptosis by biochemical DNA analysis and microscopic examination of fresh granulosa cell morphology with the established method of detecting atresia by histology in equine follicles. DNA extracted from granulosa cells was examined by staining with ethidium bromide and end-labelling with $\left[{ }^{32} \mathrm{P}\right]$ dideoxy-ATP, which labels the free $3^{\prime}$-end of DNA fragments. In 25 of 26 follicles $(96 \%)$ there was agreement between endlabelling and staining of DNA with ethidium bromide $(P<0.001)$. Granulosa cell apoptosis was distinguished more easily in the end-labelled samples than by staining with ethidium bromide. Histological atresia and apoptosis as detected by biochemical DNA analysis were significantly
\end{abstract}

correlated $(P<0.02)$ with 20 of 22 follicles $(91 \%)$ receiving corresponding classifications with the two methods. No follicles with granulosa cell apoptosis as detected by biochemical DNA analysis were histologically viable, but some of the histologically early atretic follicles did not display DNA laddering. Stereomicroscopic evaluation of morphology of the fresh granulosa cells was significantly correlated $(P<0.001)$ with the histological findings, with 29 of 33 follicles $(88 \%)$ receiving corresponding classifications. There was a potential error in determining follicle health by biochemical DNA analysis only, as both histologically early and late atretic follicles in some cases did not show DNA laddering. Thus, if relying solely on biochemical detection of apoptosis, severely atretic follicles could wrongly be classified as healthy follicles.

\section{Introduction}

In mares, only one or two follicles ovulate at each oestrus. There are approximately 35000 primordial follicles in the equine ovary (Driancourt et al., 1982), and as only $0.7-1.3 \%$ of the primordial follicles ovulate in the lifetime of a mare, the remaining $99 \%$ of the follicles become atretic and are eliminated from the ovary. Therefore, the equine ovary will always contain a mixture of healthy, growing follicles along with many regressing follicles. Information about the health status of follicles is valuable when studying a multitude of physiological processes in the follicle such as hormone production by granulosa cells, growth and selection of follicles, and maturation of the oocyte. Follicles have been classified as healthy or atretic in mares on the basis of hormone content of follicular fluid (Kenney et al., 1979) and concentrations of different insulin-like growth factor binding proteins (Gerard and Monget, 1998), as well as by histological evaluation (Driancourt, 1979; Kenney et al., 1979). Apoptosis has been reported in granulosa cells of equine follicles (Pedersen et al., 2000). None of the

Email: hgp@kvl.dk published studies on the histology of equine follicles has described apoptotic features in granulosa cells.

Apoptosis is a form of physiological cell death and appears to require gene expression (Schwartz and Osborne, 1993; Schwartzman and Cidlowski, 1993). Physiological cell death occurs in tissues, such as ovarian follicles, that undergo rapid physical changes. Apoptosis can be detected by staining DNA with ethidium bromide; end-labelling with $\left[{ }^{32} \mathrm{P}\right]$ dideoxy-ATP, which labels the free $3^{\prime}$-end of DNA fragments, followed by radiography (Tilly and Hsueh, 1993); or end-labelling of DNA fragments in individual cells in situ (Ansari et al., 1993), enabling histological detection, as well as a degree of quantitative determination of apoptosis.

The aims of this study were to compare histology of the follicle wall, as a previously established method for detecting atresia, with: (1) DNA analysis as examined by staining with ethidium bromide or by end-labelling; and (2) morphology of freshly isolated granulosa cells.

\section{Materials and Methods}

Ovaries were obtained from horses and ponies after slaughter or after ovariectomy performed under 
appropriate sedation and analgesia using the method described by Colbern and Reagan (1987). All experimental animal procedures were carried out under the Animal (Scientific Procedures) Act, 1986. The animals weighed between 198-600 kg and were aged from 2 to $>20$ years. Samples from slaughtered animals were collected at an abattoir.

\section{Ovary processing}

The ovaries were placed in M199 with Hank's salts and 25 mmol Hepes $\mathrm{I}^{-1}$ (Gibco BRL, Life Technologies Ltd, Paisley) at $30-37^{\circ} \mathrm{C}$ until processing. A $5 \mathrm{~mm} \times$ $5 \mathrm{~mm}$ section of the follicular wall was dissected out and fixed in $10 \%$ buffered formalin for $24 \mathrm{~h}$ for subsequent histological evaluation. The inner wall of the follicle was scraped with a bone curette to release the granulosa cells. The granulosa cells were flushed off with M199 with Hank's salts and evaluated using a stereomicroscope. After evaluation the granulosa cells were pelleted by centrifugation at $2000 \mathrm{~g}$ for $30 \mathrm{~s}$ at room temperature $\left(18-20^{\circ} \mathrm{C}\right)$, snap frozen and stored at $-70^{\circ} \mathrm{C}$ until DNA extraction. The method of granulosa cell DNA extraction has been described by Pedersen et al. (2000).

\section{DNA analysis by ethidium bromide staining of extracted DNA}

In samples with $6 \mu \mathrm{g}$ or more DNA, the DNA fractions were separated by agarose gel electrophoresis, using 6-10 $\mu \mathrm{g}$ DNA from one follicle per lane in a $1.5 \%$ agarose gel. The DNA was stained with ethidium bromide incorporated in the gel $\left(1 \mathrm{mg} \mathrm{ml}^{-1}\right)$ and visualized with ultraviolet light using a transilluminator connected to an image analysis system (IS 500 Gel Documentation System, Alpha Innotech Ltd, Cannock).

\section{DNA analysis by $3^{\prime}$-end labelling of extracted DNA}

The DNA in samples with 2-5 $\mu$ g DNA was 3'end labelled as described by Pedersen et al. (2000). Briefly, $2 \mu \mathrm{g}$ DNA was labelled at the 3'-end with $2 \mu \mathrm{l}$ $\left.{ }^{32} \mathrm{P}\right]$ dideoxy-ATP $(50 \mu \mathrm{Ci})$ (Amersham Life Science Ltd, Little Chalfont). The end-labelled DNA fragments were separated by agarose gel electrophoresis and the gel was exposed to Kodak X-ray film.

\section{Apoptotic and non-apoptotic DNA controls}

DNA from freshly isolated murine thymocytes was used on each gel as a negative (non-apoptotic) control and DNA from murine thymocytes was incubated for $24 \mathrm{~h}$ with dexamethasone $\left(100 \mu \mathrm{g}\right.$ dexamethasone $\mathrm{ml}^{-1}$ culture medium; Sigma-Aldrich Co., Poole) used as a positive (apoptotic) control (Wyllie, 1980; Cohen and Duke, 1984).

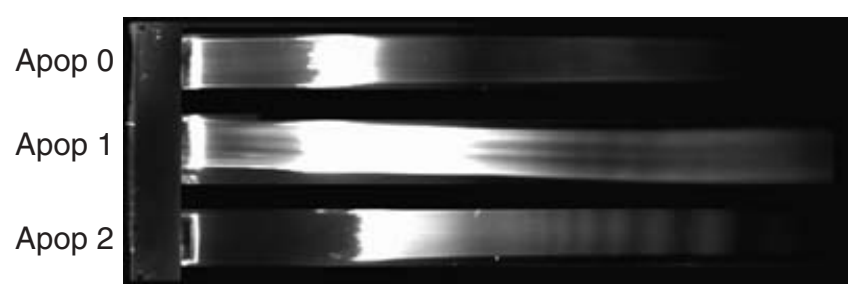

Fig. 1. Apoptosis grades in DNA from equine follicles after electrophoresis on a gel containing ethidium bromide. Apop 0: no DNA laddering; Apop 1: smearing of DNA but with underlying DNA laddering; Apop 2: distinct DNA laddering.

\section{DNA analysis grading system}

Follicles were classified as containing apoptotic granulosa cells when the characteristic laddering of internucleosomal DNA fragments was detected (Wyllie, 1980). Follicles with no detectable laddering were classified as having non-apoptotic granulosa cells (Apop $0)$. Follicles with smearing of DNA in the lane but with underlying laddering were classified as having apoptotic granulosa cells (Apop 1). Follicles with distinct laddering were classified as distinctly apoptotic (Apop 2) (Fig. 1). The non-apoptotic control mouse thymocytes were graded as Apop 0. The apoptotic control mouse thymocytes were graded as Apop 2.

\section{Morphology of freshly retrieved granulosa cells}

The granulosa cells were released from the follicle with a bone curette. The cells were then gently flushed into a Petri dish and kept in M199 with Hank's salts for no longer than $5 \mathrm{~min}$ whilst the sheets of granulosa cells were evaluated using a stereomicroscope $(\times 10$ 40 magnification) before snap freezing. Follicles with many granulosa cells in tight connection with each other, in large light brown sheets, were classified as containing compact granulosa cells. Follicles with granulosa cells other than compact, such as mucified, expanded granulosa cells or granulosa cells within a gelatinous substance, were classified as containing expanded granulosa cells.

\section{Histological detection of atresia}

Samples of follicular wall were fixed in buffered formalin for $24 \mathrm{~h}$ and stored in $70 \%$ alcohol until they were processed. The samples were dehydrated in alcohol and then cedar wood oil, transferred to toluene and finally embedded in paraffin wax. Consecutive sections $(5-7 \mu \mathrm{m})$ were cut using a microtome, mounted on gelatine-coated slides and dried overnight in an oven before staining. The sections were stained with Harris haematoxylin and washed with Scott's tap water substitute. Counterstaining was performed with Putt's 

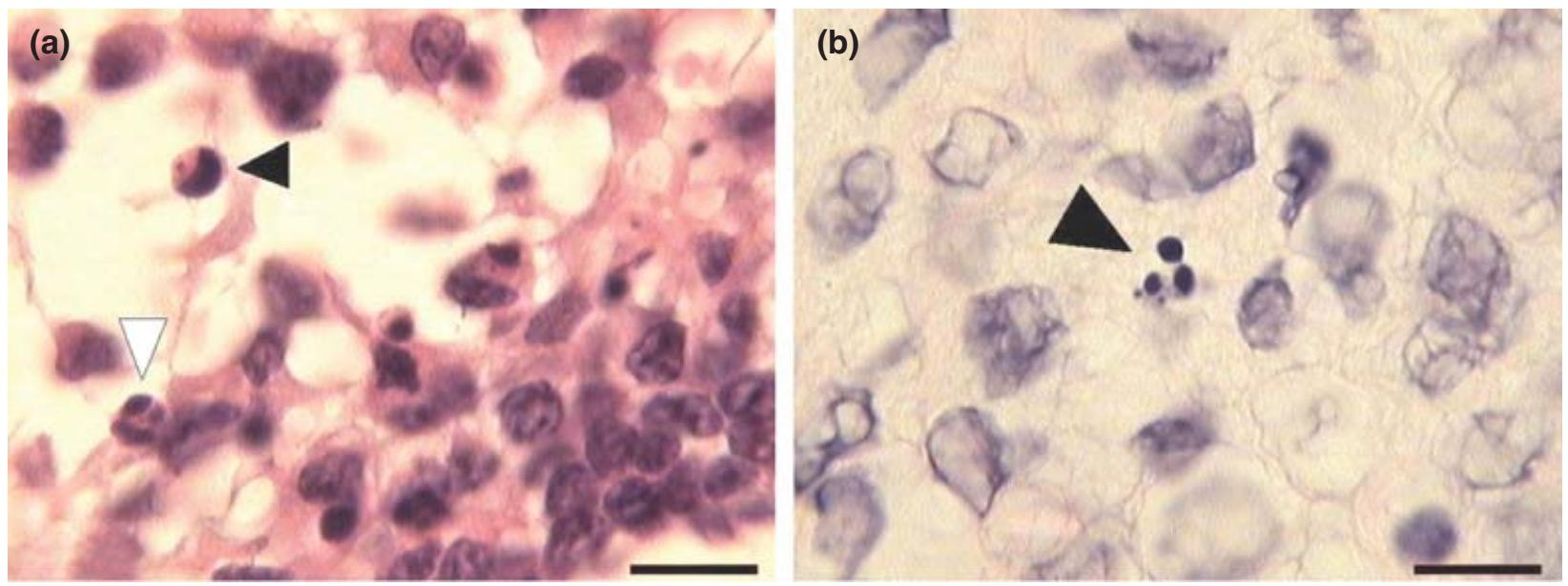

Fig. 2. Apoptotic cells in equine follicle wall stained with haematoxylin and eosin. (a) Granulosa cells with crescent-shaped chromatin in the nucleus (black arrowhead) and fragmentation of the nucleus (white arrowhead). (b) Theca cell with fragmentation of the nucleus (black arrowhead). Scale bars represent $10 \mu \mathrm{m}$.

eosin. The samples were washed in water, dehydrated, cleared and mounted in DPX mountant (BDH, Poole).

Sections of follicular wall were evaluated with a light microscope at $\times 20, \times 40$ and $\times 100$ (oil immersion). One hundred cells were counted in each of ten sections per follicle. The percentage of apoptotic nuclei was calculated. Atresia in the follicle wall was evaluated as described by Kenney et al. (1979), but with the modification that fragmented nuclei were classed as apoptotic (Fig. 2): Atresia 0: viable follicles with no signs of atresia; Atresia 1: pyknotic and apoptotic granulosa cells were present but there was no reduction in granulosa cell layer thickness or change in the theca cell layer; Atresia 2: both granulosa and theca cell layers contained pyknotic and apoptotic cells, and there was a hyaline membrane between the granulosa and the theca cell layers (only a mono- or bilayer of granulosa cells remained); and Atresia 3: a few pyknotic and apoptotic granulosa cells or fibroblast-like cells were present along with a thick hyaline membrane.

\section{Statistical analysis}

Fisher's exact probability test was used to establish the association between DNA end-labelling versus staining with ethidium bromide, ethidium bromide staining of DNA versus histology, and histology versus fresh granulosa cell morphology. The data were analysed using a $2 \times 2$ test. The null hypothesis was that the distribution of the data was random. If the $P$ value was equal to or less than 0.05 , the null hypothesis was rejected and an association between the methods was present. A chisquared test was applied when testing for an association between staining of DNA with ethidium bromide and fresh granulosa cell morphology. The null hypothesis was that the data were randomly distributed. (a)

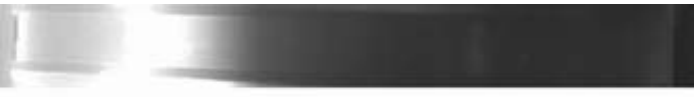

(b)

(c)
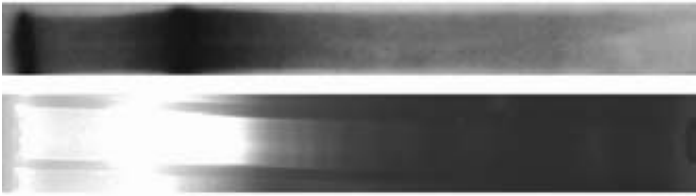

(d)

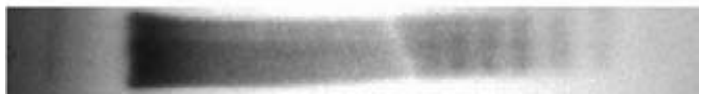

Fig. 3. Equine DNA analysis by staining DNA with ethidium bromide and 3 '-end labelling of DNA. (a) DNA stained with ethidium bromide with no apoptotic laddering. (b) 3'-end labelled DNA from the same follicle as in (a). (c) DNA stained with ethidium bromide with apoptotic laddering. (d) 3'-end labelled DNA from the same follicle as in (c).

\section{Results}

Experiment 1: comparison of DNA 3'-end labelling and staining with ethidium bromide

It was hypothesized that in samples in which little DNA was extracted, 3'-end labelling would be necessary, as this technique requires less DNA than staining with ethidium bromide. Follicles were subjected to 3'-end labelling as well as staining with ethidium bromide to establish the congruity between the two methods (Fig. 3). Two $\mu$ g DNA was used for 3'-end labelling, and $10 \mu \mathrm{g}$ DNA was used for staining with ethidium bromide. In 25 of 26 follicles (96\%) there was agreement between the end-labelling and staining with ethidium bromide $(P<0.001)$. Sixteen follicles were classified as having non-apoptotic granulosa cells and nine contained apoptotic granulosa cells with both methods. One follicle was classified as having apoptotic granulosa cells after 

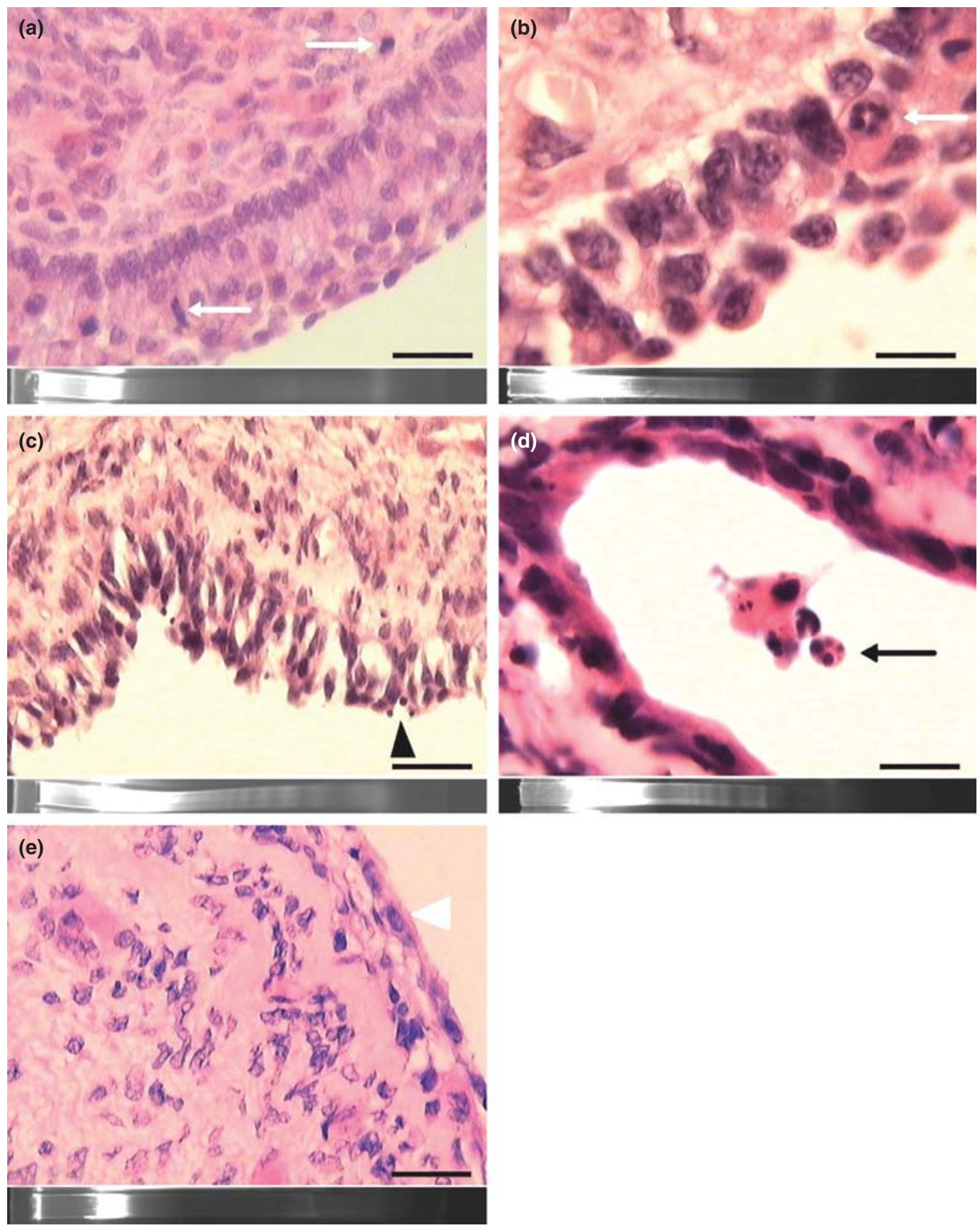

Fig. 4. Sections of equine follicle wall and corresponding ethidium bromide agarose gels for detection of apoptosis of the same follicles. (a), (b), (c), (d) and (e) show examples of sections of follicles of different health status stained with haematoxylin and eosin, and insets of DNA stained with ethidium bromide extracted from the corresponding follicles. (a) Atresia 0: non-atretic follicle with mitotic cells (arrows); inset, Apop 0: no DNA laddering. (b) Atresia 1: early atretic follicle with apoptotic granulosa cell (arrow); inset, Apop 1: DNA laddering. (c) Atresia 2: atretic follicle with pyknotic nuclei (arrowhead); inset, Apop 2: distinct DNA laddering. 
Table 1. Histological evaluation of atresia versus presence of apoptosis as detected by DNA laddering in equine follicles

\begin{tabular}{lrc}
\hline Atresia stage (histology) & $n$ & Follicles with DNA laddering (\%) \\
\hline 0 & 12 & $0^{\mathrm{a}}$ \\
1 & 3 & $66.7^{\mathrm{b}}$ \\
2 & 2 & $100^{\mathrm{b}}$ \\
3 & 5 & $80^{\mathrm{b}}$ \\
\hline
\end{tabular}

a,b $: P<0.02$.

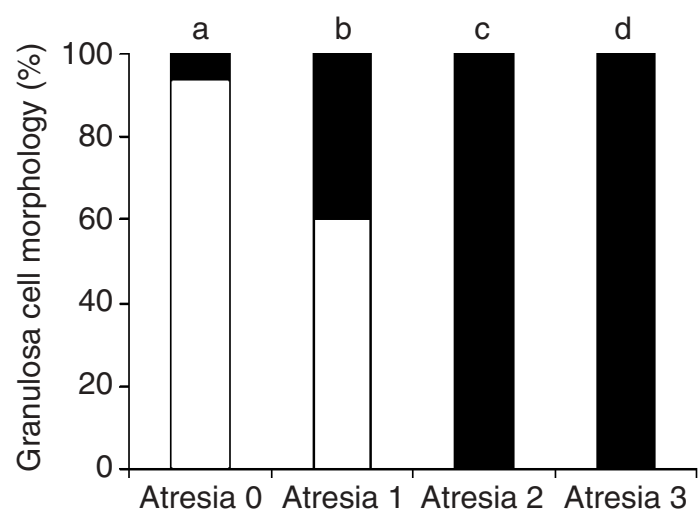

Fig. 5. Morphology of freshly isolated equine granulosa cells in relation to histological evaluation of sectioned follicular wall stained with haematoxylin and eosin. $\square$ : Compact granulosa cells, 口: expanded granulosa cells. Letters denote significant difference: a-c $(P=0.02)$, a-d $(P<0.001)$ and b-d $(P=0.03)$. No significant differences were found for $a-b, b-c$ and $c-d$. The reason for the lack of significance between $b-c$ is the small number of follicles in Atresia 2. Numbers of follicles in each group: Atresia $0(n=17)$, Atresia $1(n=5)$, Atresia $2(n=2)$ and Atresia $3(n=9)$.

end-labelling, whereas the ethidium bromide technique did not detect apoptosis in this follicle. In three of nine $(33 \%)$ follicles with apoptotic granulosa cells, the endlabelling showed more distinct evidence of apoptosis than did the staining with ethidium bromide.

\section{Experiment 2: biochemical DNA analysis in relation to histology of the follicular wall}

Follicular wall sections and fresh granulosa cells were collected from the same follicles to compare biochemical DNA analysis with histological findings. Histological atresia and apoptosis as detected by DNA laddering were significantly correlated $(P<0.02)$, with 20 of 22 follicles processed $(91 \%)$ receiving corresponding classifications in the two methods (Table 1 and Fig. 4). Four other follicles were originally included in the experiment, but they were classed as Atresia 3 and were

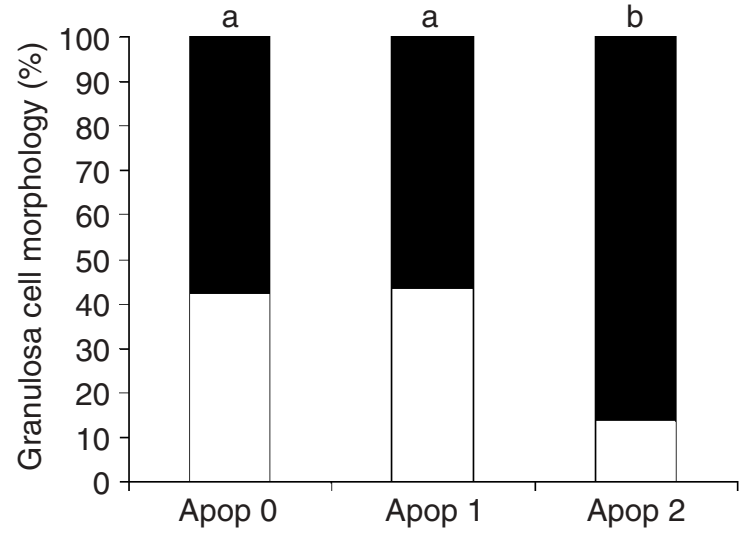

Fig. 6. Relationship between granulosa cell apoptosis as detected by DNA laddering and granulosa cell morphology of freshly isolated cells in mares. $\square$ : compact granulosa cells, $\mathbf{\square}$ : expanded granulosa cells. Letters a and b denote significant difference $(P<$ $0.01)$. Number of follicles in each group: Apop $0(n=207)$, Apop $1(n=101)$ and Apop $2(n=43)$.

so degenerated that they contained too few granulosa cells to yield enough DNA for biochemical analysis. Histological examination revealed that these follicles contained more than 95\% fibroblast-like cells. In Atresia 3 , four of the five follicles showed apoptosis as detected by DNA laddering. These four follicles had 58-75\% apoptotic granulosa cells by histological evaluation. The remaining follicle was classified as non-apoptotic after DNA analysis. Histological examination revealed that this follicle contained $100 \%$ fibroblast-like cells rather than granulosa cells.

Experiment 3: morphology of freshly retrieved granulosa cells in relation to histology of the follicular wall

Follicular wall and fresh granulosa cells were collected from the same follicles to compare histology of the follicular wall with morphology of fresh granulosa cells evaluated by stereomicroscopy immediately after recovery. A total of 33 follicles was evaluated. The stereomicroscopic evaluation of the fresh granulosa cells was significantly correlated $(P=0.03)$ with the histological findings (Fig. 5). Only three of 19 (16\%) follicles with compact granulosa cells were histologically atretic follicles. In follicles with expanded granulosa cells, only one of $13(8 \%)$ follicles was not histologically atretic.

Experiment 4: morphology of freshly retrieved granulosa cells in relation to biochemical DNA analysis

The correlation between the morphology of freshly isolated granulosa cells and biochemical DNA analysis 
was examined. In total, 351 follicles were examined for granulosa cell morphology and apoptosis as detected by DNA laddering (Fig. 6). There was no significant difference in distribution of compact granulosa cells and expanded granulosa cells between Apop 0 and Apop 1, but there was a significant difference between Apop 0 or 1 and Apop $2(P<0.01)$. Five of six follicles with very few granulosa cells as seen by stereomicroscopy of fresh granulosa cells were classified as having nonapoptotic granulosa cells as detected by staining with ethidium bromide.

\section{Discussion}

The present study has shown that evaluation of follicle health by detection of apoptosis by DNA laddering is well correlated with histology of the follicle wall apart from cases of severe atresia of the follicles, thus creating a potential error in classifying atretic follicles as healthy if not using other parameters of follicle health.

In the majority of cases, the two biochemical methods of $3^{\prime}$-end labelling and staining with ethidium bromide correlated well in classification of follicles as containing apoptotic or non-apoptotic granulosa cells. There was a tendency to distinguish the apoptosis more easily in the 3 '-end labelled samples. End-labelling specifically visualizes the $3^{\prime}$-ends of broken DNA strands, which makes the method more sensitive for detection of apoptosis than staining with ethidium bromide, which stains DNA in general. In agreement with the present study, Jolly et al. (1994) reported that the 3 '-end labelling method in bovine follicles detects apoptosis in some samples classified as non-apoptotic after staining with ethidium bromide.

Evaluation of freshly retrieved granulosa cells is a quick method for obtaining an indication of the health status of a follicle. The stereomicroscopic evaluation of the fresh granulosa cells was significantly correlated with the histological findings. The best correlation was in cases of non-atretic follicles and severely atretic follicles. Morphology of fresh granulosa cells was relatively insensitive compared with histology when detecting early atresia. A characteristic of cells undergoing apoptosis is that junctions with neighbouring cells are disrupted (Duvall and Wyllie, 1986). Therefore, the finding that almost all follicles with any degree of granulosa cell expansion were histologically atretic indicated that when the granulosa cells were no longer in close contact with each other in large sheets, the follicle of origin had started to undergo atresia.

The stereomicroscopic evaluation of fresh granulosa cells was also significantly correlated with results obtained by biochemical DNA analysis. The presence of predominantly expanded granulosa cells in the group of follicles with Apop 2 indicated that severe apoptosis was reflected morphologically in the granulosa cells.
Detection of apoptosis by biochemical DNA analysis was significantly correlated with classification of atresia by histology in the present study. Similarly, a study in cattle demonstrated that with increasing degrees of histological atresia, the proportion of apoptotic cells as detected by flow cytometry increases (Blondin et al., 1996). In a study in ewes, the same granulosa cells were stained initially with haematoxylin and eosin, washed, and then stained by TdT-mediated dUTP nickend labelling, which stains fragmented DNA in cells. The results showed that the morphology of the granulosa cells classified as apoptotic in haematoxylin and eosin sections contained fragmented DNA and were indeed apoptotic (Jolly et al., 1997).

The present study determined that examining follicles by biochemical DNA analysis only may be misleading as early and late atresia, as detected by histology, was not always detected by biochemical DNA analysis. No follicles with granulosa cell apoptosis, as detected by DNA laddering, were non-atretic by histological examination, but some of the early atretic follicles as determined by histology did not show apoptotic laddering, indicating that biochemical DNA analysis is less sensitive. Perhaps at this stage there are too few apoptotic cells to be detected by DNA analysis. In the present study, histological evidence of apoptosis with more than $14 \%$ apoptotic granulosa cells corresponded well to the presence of DNA laddering. In a study of apoptosis in pig follicles, the follicles were biochemically atretic when more than $10 \%$ apoptotic cells were present (Guthrie et al., 1994). Another explanation for not detecting biochemical apoptosis in early atretic follicles in the present study may be that the DNA was only in the process of being degraded, although in rat follicles, DNA fragmentation is thought to occur before histological changes are detected (Nahum et al., 1996). A study on atresia in bovine follicles indicates that granulosa cells may also die by pathways other than apoptosis as DNA fragmentation is not necessarily present during atresia (Van Wezel et al., 1999).

An important finding of the present study is that follicles with very few freshly isolated granulosa cells displayed no apoptosis as detected by DNA laddering. This is in agreement with the histological findings in which the granulosa cells of severely atretic follicles (Atresia 3) had almost disappeared and therefore did not show any DNA laddering. These findings indicate that follicles classified by biochemical DNA analysis as containing non-apoptotic granulosa cells were a mixed population of truly healthy follicles and highly atretic follicles. Whilst there are several possible explanations for the observed result, the most likely is that the cells from which DNA was extracted were not granulosa cells as these had perished, but rather fibroblast-like cells. Thus, there is a potential error in classifying follicles only by biochemical DNA analysis, as some advanced atretic follicles could be classified wrongly as healthy, 
thereby giving misleading experimental results. It is necessary to evaluate follicles with no biochemical apoptosis by parameters other than DNA fragmentation, such as histological evaluation or fresh granulosa cell morphology, to avoid this potential mistake.

In conclusion, this study has demonstrated that detection of apoptosis by biochemical DNA analysis and description of fresh granulosa cell morphology are generally in good agreement with the established method of histological detection of follicular health, but that the tested biochemical and cytological methods have limitations compared with histology. The more parameters that are used in conjunction with each other, the more accurate is the interpretation of the state of the follicle, particularly with regards to early and late atretic follicles.

The authors wish to thank J. Binnie for excellent technical assistance with the histology sections. H. G. Pedersen was in receipt of the James Tindall Faculty Scholarship, University of Edinburgh, UK.

\section{References}

Ansari B, Coates PJ, Greenstein BD and Hall PA (1993) In situ end-labelling detects DNA strand breaks in apoptosis and other physiological and pathological states Journal of Pathology 170 1-8

Blondin P, Dufour M and Sirard MA (1996) Analysis of atresia in bovine follicles using different methods: flow cytometry, enzyme-linked immunosorbent assay, and classic histology Biology of Reproduction 54 631-637

Cohen JJ and Duke RC (1984) Glucocorticoid activation of a calciumdependent endonuclease in thymocyte nuclei leads to cell death Journal of Immunology 132 38-42

Colbern GT and Reagan WJ (1987) Ovariectomy by colpotomy in mares Compendium on Continuing Education for the Practicing Veterinarian 9 1035-1038

Driancourt MA (1979) Follicular kinetics in the mare ovary Annales de Biologie Animale, Biochimie, Biophysique 19 1443-1453

Driancourt MA, Paris A, Roux C, Mariana JC and Palmer E (1982) Ovarian follicular populations in pony and saddle-type mares Reproduction, Nutrition, Development 22 1035-1047

Duvall E and Wyllie AH (1986) Death and the cell Immunology Today 7 115-118
Gerard N and Monget P (1998) Intrafollicular insulin-like growth factorbinding protein levels in equine ovarian follicles during preovulatory maturation and regression Biology of Reproduction 58 15081514

Guthrie HD, Welch GR, Cooper BS, Zakaria AD and Johnson LA (1994) Flow cytometric determination of degraded deoxyribonucleic acid in granulosa cells to identify atretic follicles during preovulatory maturation in the pig Biology of Reproduction 50 1303-1311

Jolly PD, Tisdall DJ, Heath DA, Lun S and McNatty KP (1994) Apoptosis in bovine granulosa cells in relation to steroid synthesis, cyclic adenosine $3^{\prime} 5^{\prime}$-monophosphate response to follicle-stimulating hormone and luteinizing hormone, and follicular atresia Biology of Reproduction $\mathbf{5 1}$ 934-944

Jolly PD, Smith PR, Heath DA, Hudson NL, Lun S, Still LA, Watts CH and McNatty KP (1997) Morphological evidence of apoptosis and the prevalence of apoptotic versus mitotic cells in the membrana granulosa of ovarian follicles during spontaneous and induced atresia in ewes Biology of Reproduction $\mathbf{5 6} 837-846$

Kenney RM, Condon W, Ganjam VK and Channing C (1979) Morphological and biochemical correlates of equine ovarian follicles as a function of their state of viability or atresia Journal of Reproduction and Fertility Supplement 27 163-171

Nahum R, Beyth Y, Chun SY, Hsueh AJ and Tsafriri A (1996) Early onset of deoxyribonucleic acid fragmentation during atresia of preovulatory ovarian follicles in rats Biology of Reproduction 55 1075-1080

Pedersen HG, Watson ED and Telfer EE (2000) Apoptosis in equine granulosa cells and its relationship to cumulus expansion and oocyte chromatin configuration in ovarian follicles Journal of Reproduction and Fertility Supplement $\mathbf{5 6}$ 455-462

Schwartz LM and Osborne BA (1993) Programmed cell death, apoptosis and killer genes Immunology Today 14 582-590

Schwartzman RA and Cidlowski JA (1993) Apoptosis: the biochemistry and molecular biology of programmed cell death Endocrinology Reviews 14 133-151

Tilly JL and Hsueh AJ (1993) Microscale autoradiographic method for the qualitative and quantitative analysis of apoptotic DNA fragmentation Journal of Cell Physiology 154 519-526

Van Wezel IL, Dharmarajan AM, Lavranos TC and Rodgers RJ (1999) Evidence for alternative pathways of granulosa cell death in healthy and slightly atretic bovine antral follicles Endocrinology 1402602 2612

Wyllie AH (1980) Glucocorticoid-induced thymocyte apoptosis is associated with endogenous endonuclease activation Nature 284 555-556

Received 10 April 2002

First decision 12 July 2002.

Revised manuscript received 18 November 2002.

Accepted 28 November 2002. 